\title{
Innovative Capacities of Shipbuilding Organizations Manufacturing Composite Ships
}

\author{
Violeta Šugar \\ Juraj Dobrila University of Pula, Croatia \\ Josip Zanze \\ Juraj Dobrila University of Pula, Croatia
}

\begin{abstract}
During the transitional period at the end of the 20th century, Croatian small composite shipbuilding (SCS) had merely 27 models. Still, at the end of the first decade of the 21 st century, this innovative industry showed resilience and readiness to adapt to the new business conditions and created 237 basic models. The main goal of the research was the assessment of the innovative capacity of SCS in Croatia. The research was carried out via survey and interviews. It included 73 SCS organisations, based on the main hypothesis that there is a positive relationship between the innovative capacity and innovative appearances (innovative management, innovation culture, innovative policy, and innovative factors) as well as the performance of the organization. The testing was performed with the Pearson's correlation coefficient, the ANOVA and the post hoc LSD test resulted in the confirmation of the main and the three ancillary hypotheses. For the first time in Croatia, a new model of assessment of innovative capacities and innovative phenomena is presented, aiming to raise awareness of the need to strengthen the innovative capacities as a basis for the development of SCS.
\end{abstract}

Keywords: small composite shipbuilding, innovative capacity, innovative management, innovation culture, innovative policy, innovative factors, innovation ecosystem, Croatia

JEL classification: D02, 014, O31, O32

Paper type: Research article

Received: Apr 25, 2021

Accepted: Jun 2, 2021

DOI: 10.54820/OPUE2583 


\section{Introduction}

Innovation is an essential driver of economic progress and social wellbeing and a key source of current and long-term competitive advantage (OECD, 2021). The innovation ecosystem as an economic environment with reciprocal exchanges, with different types of relationships acting as a system (Gawer et al., 2013, Letaifa et al., 2013) is a network of various players, intermediaries, facilitators, and resources, who all play a role in taking a great idea to transformative impact at scale.

Regarding shipbuilding, as a complex, economically significant, and competitive industry, there has still been little research (Lee et al., 2014, Saverhoff, 2013, Wade, 2012). Shipbuilding is a very demanding production and requires a lot of knowledge. Still, at the same time, it is a propulsive industry and development driver of a vast range of human activities. With the mass construction of large steel ships and the growth of shipyards into big industrial plants, the notion of small shipbuilding appeared in the 20th century to separate this activity from the income and number of workers of the predominant part of shipbuilding. There has been a tremendously rapid technological development in small shipbuilding in the last twenty years, especially regarding new materials, such as Kevlar and carbon fibre (Rubino et al., 2020). However, the process of producing composite castings (fibre-reinforced polymers, commonly called fibreglass) still depends on the most precise and careful manufacture. Modern shipbuilding consists of thousand of components installed in a large ship and relies on many other industries (procurement of raw materials, devices, parts, etc.). Small composite shipbuilding (SCS), although with fewer components, also belongs to a sophisticated production, especially in terms of the ship's built-in equipment, starting from the engine to the navigation system. The three basic materials used in SCS production are polyester resin, gelcoat, and fiberglass. While large shipbuilding takes place only by the sea, the SCS could also be found in the interior of Croatia (Zanze, 2021). Croatian and other European shipyards should offer not only customized high-tech ships of the best quality but also technical service packages adding further value for their customers to improve their global market position (Saverhoff, 2013).

Since 2009 the shipbuilding industry has been hit heavily by the economic downturn (OECD, 2009). The European Economic and Social Committee was very concerned at the profound crisis affecting the EU shipbuilding industry, characterised by a lack of new orders, major problems in financing existing orders, overcapacity, and irreversible jobs losses (Tenold, 2019). Therefore, to initiate the innovative process in SCS organizations, in addition to the technical-technological and production system, there is a need for new organizational models, innovative marketing, management, and organisational strategies, to raise innovation culture, innovative policy, and innovative factors to a higher level, together with the innovative capacity within each SCS organization. The possible crisis exit strategy for the SCS organisations could be expanding the innovative capacities, which was the goal of this research.

By 2010, there were at least 167 small shipbuilding organizations registered in Croatia (Zanze, 2021), among which around 100 of those in the composite (commonly called small fiberglass shipbuilding) with 237 basic moulds. Due to the crisis, 30 of them were shut down. A survey carried out for this research covered 73 SCS organizations. They produce 307 basic models, which with superstructure modifications, give more than 500 composite models to produce ships of all sizes. The research aimed to assess the state of innovative capacities of the SCS organizations. Two questions were raised: 1) how does innovative capacity affect the innovative appearances of the organization: innovative management (IM), 
innovation culture (ICU), innovative policy (IP), and innovative factors (IF); 2) how does innovative capacity affect the performance (BP) of SCS organizations, as well as the main hypothesis: there is a positive correlation between IC, IM, ICU, IP, IF and BP of SCS organisations. Following the Introduction, the research methodology and results are elaborated, the limitations of the research, recommendations for the follow-up, and finally, the conclusion sums up the scientific contribution and importance of this research.

\section{Methodology}

Both desk and empirical research were carried out. There are very few available sources dealing with small shipbuilding in Croatia, especially the SCS, among which the boat fair catalogues (such as Croatia Nautic Show, Rijeka Boat Show, and Biograd Boat Show), the professional trade magazines (such as More and Moja brodica), the official web pages of the SCS organisations, as well as the scarce scientific databases. The empirical research was conducted via an originally designed questionnaire, distributed to almost all SCS organizations in Croatia by email and/or at the nautical fairs (Rijeka Boat Show 2019 and Biograd Boat Show 2019) was possible to combine the questionnaire and interviews with the SCS representatives. The interviews were performed using the same questions as in questionnaires, so they were just the additional aid for getting a better response rate.

This research, for the first time in Croatia, provided a new methodology for assessing the innovative capacity (IC) of SCS organizations and the relationship of IC with the 4 appearances: innovative management (IM), innovation culture (ICU), innovative policy (IP), innovative factors (IF) and business performance (BP) of SCS organizations. The research started with the following main hypothesis: there is a positive correlation between IC, IM, ICU, IP, IF, and BP of SCS organisations and 5 auxiliary hypotheses: 1) there is a positive correlation between IC and IM;2) there is a positive correlation between IC and ICU; 3 ) there is a positive correlation between IC and IP; 4) there is a positive correlation between IC and IF; 5) there is a positive correlation between IC and BP of SCS organisations in Croatia.

The IC, as the ability to create and develop innovations, consists of product innovation, process innovation, marketing innovation, organizational innovation, technology innovation, and strategy innovation (Tidd et al., 2020, OECD, 2018, Ganzer et al., 2017, Bacchiega et al., 2011). The IM is the capacity of the meaningful search for the best solution and represents the continuous updating of various aspects of activities of an organisation (Kiseleva et al., 2017). According to Rao et al. (2013), the ICU rests on a foundation of six building blocks: resources, processes, values, behaviour, climate, and success of an organisation. The IP refers to an innovative approach to managerial decision-making regarding strategy, product and process development, marketing, organization, technology, and all other business activities (Zanze, 2021, Selyutina, 2018). The IF determines the direction of the innovative setting development in SCS organisations (Stawasz, 2019), and the BP represents both qualitative and quantitative outcomes of incremental and radical innovations.

A questionnaire with 30 questions and 260 sub-questions distributed in 8 variable groups was designed (Table 1). The first group referred to the basic information about the organization; the second group deals with the BP results; the third group of questions refers to IC, the fourth to IM, the fifth to ICU, the sixth to IP, the seventh to IF, and the eighth group to subjective assessment of the state of the organization. 
Table 1

Overview of the Variables and Indicators

\begin{tabular}{|c|c|c|c|c|}
\hline \multicolumn{2}{|c|}{ Group / variables } & \multicolumn{2}{|r|}{ Question / topic } & \multirow{2}{*}{$\begin{array}{c}\begin{array}{c}\text { Indicators } \\
\text { (sub- } \\
\text { questions) }\end{array} \\
11\end{array}$} \\
\hline 1 & Basic & 1 & General & \\
\hline & information & 2 & Human resources & 5 \\
\hline & about the & 3 & Business & 12 \\
\hline & organization & 4 & Molds & 18 \\
\hline \multirow[t]{4}{*}{2} & $\begin{array}{l}\text { Business } \\
\text { performance }\end{array}$ & 5 & $\begin{array}{l}\text { Qualitative effects of incremental } \\
\text { innovations }\end{array}$ & 10 \\
\hline & & 6 & $\begin{array}{l}\text { Qualitative effects of radical } \\
\text { innovations }\end{array}$ & 10 \\
\hline & & 7 & $\begin{array}{l}\text { Quantitative effects of incremental } \\
\text { innovations }\end{array}$ & 10 \\
\hline & & 8 & $\begin{array}{l}\text { Quantitative effects of radical } \\
\text { innovations }\end{array}$ & 10 \\
\hline \multirow[t]{6}{*}{3} & Innovative & 9 & Product innovation & 12 \\
\hline & capacity & 10 & Process innovation & 12 \\
\hline & & 11 & Marketing innovation & 12 \\
\hline & & 12 & Organisation innovation & 12 \\
\hline & & 13 & Innovative technology & 12 \\
\hline & & 14 & Innovative strategy & 12 \\
\hline \multirow[t]{6}{*}{4} & Innovative & 15 & Work plan & 6 \\
\hline & managment & 16 & Key competencies & 6 \\
\hline & & 17 & Key activities & 6 \\
\hline & & 18 & Key processes & 6 \\
\hline & & 19 & Incremental innovations & 6 \\
\hline & & 20 & Radical innovations & 6 \\
\hline \multirow[t]{3}{*}{5} & Innovation & 21 & Most needed innovations & 6 \\
\hline & culture & 22 & Experience of the organisation & 6 \\
\hline & & 23 & Innovations in development & 6 \\
\hline \multirow[t]{3}{*}{6} & Innovative & 24 & Innovative impression & 6 \\
\hline & policy & 25 & Innovation goals & 6 \\
\hline & & 26 & Innovation factors & 6 \\
\hline \multirow[t]{3}{*}{7} & Innovative & 27 & Innovation barriers & 6 \\
\hline & factors & 28 & Innovation effects & 6 \\
\hline & & 29 & Innovation motivation & 6 \\
\hline \multirow[t]{2}{*}{8} & $\begin{array}{l}\text { State of the } \\
\text { organisation }\end{array}$ & 30 & $\begin{array}{l}\text { Subjective assessment of the } \\
\text { organisation }\end{array}$ & 12 \\
\hline & TOTAL & & & 260 \\
\hline
\end{tabular}

Source: Authors

Respondents could choose the statements from the questionnaire on a measuring scale from 1 to 10, where a value of 1 indicated complete disagreement and a value of 10 complete accordances with the statement. 40 SCS manufacturers out of 73 registered (54.79\%), owners of 247 molds $(80.46 \%$ of the total number of SCS molds in Croatia) responded to the survey, which makes the results relevant and significant. The obtained answers were processed with the programs Statistica and SPSS 25 . The hypotheses were tested with the Cronbach's Alpha, Pearson's correlation, ANOVA, and LSD post hoc test. The Cronbach's Alpha test validated the hypotheses (average 0,745). 


\section{Results}

According to the Pearson's correlation (Figure 1 and Table 2), there is a statistically significant correlation between the IC and a total of 4 appearances and BP, as well as between IC and IM, IC and IP, IC, and IF. Therefore, the main and the three auxiliary hypotheses are confirmed. There is no positive correlation between the IC and ICU, and there is no significant correlation between the IC and BP of SCS organisations in Croatia. The increase in the level of IC was not accompanied by a change in the level of BP, probably because other variables are influencing BP.

Figure 1

Results of the Pearson's Correlation
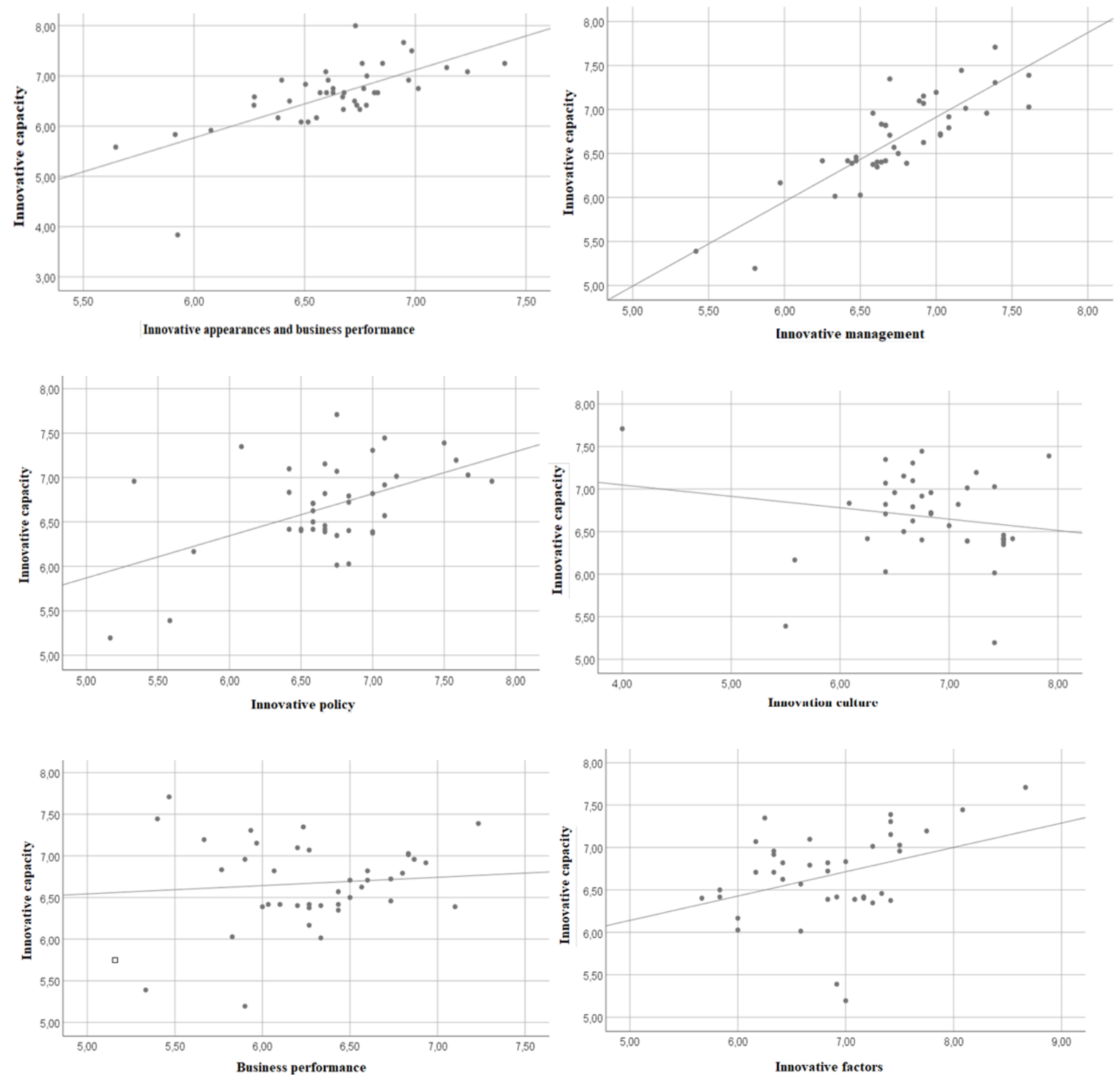

Source: Authors' work 
Figure 2

Results of the ANOVA and LSD Post Hoc Test
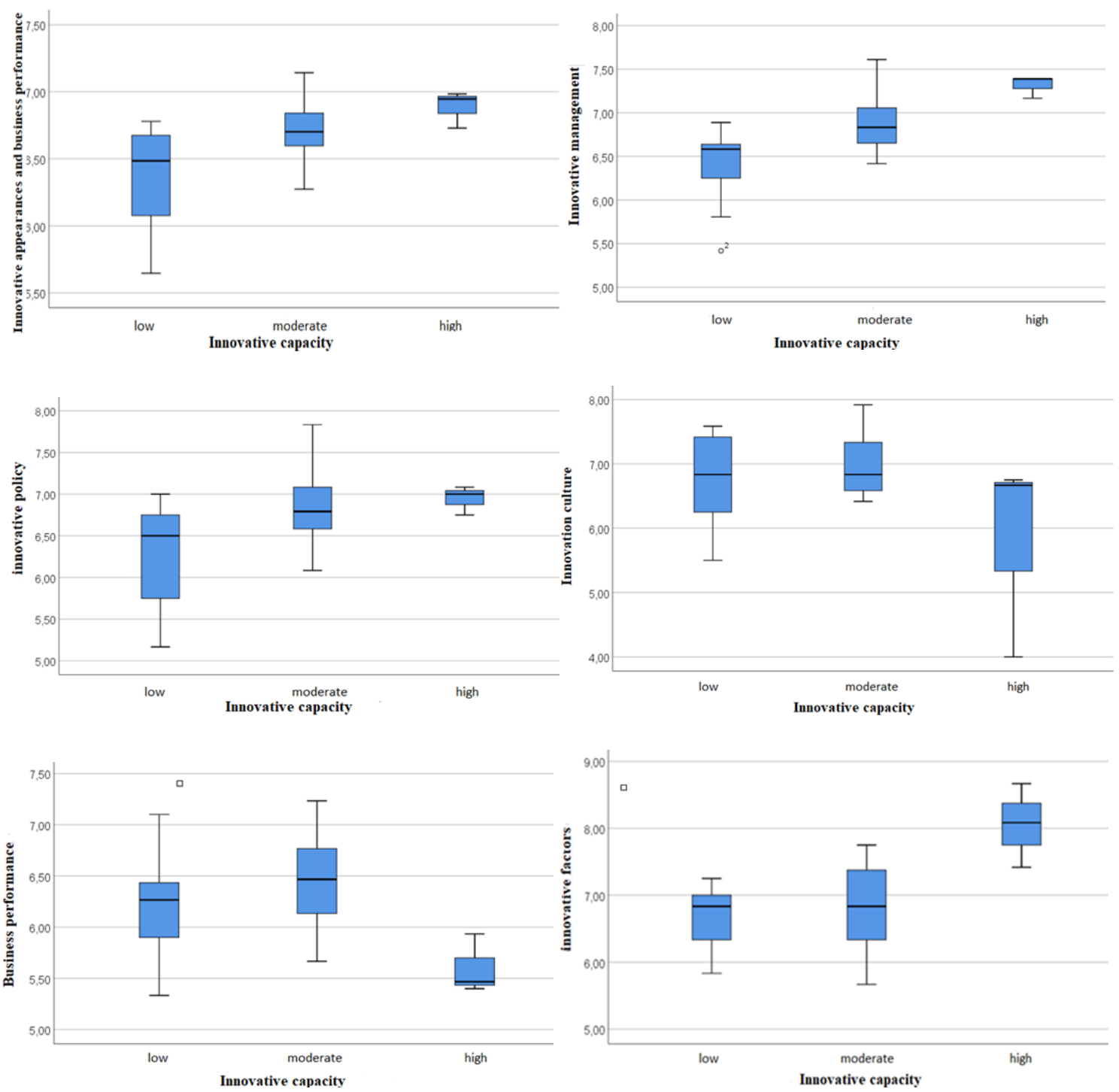

Source: Authors' work

The ANOVA and LSD post hoc test (Figure 2 and Table 2) revealed that an increase of the level of IC from low to moderate and high level contributes to a significant increase of IM, IP, and IF. As for the ICU and BP, there is a significant decrease in ICU and BP in organizations with a developed high level of IC. 
Table 2

Numerical results of the Pearson's Correlation, ANOVA, and LSD Post Hoc Test

\begin{tabular}{|c|c|c|c|}
\hline Hypotheses & $\begin{array}{l}\text { Pearson's } \\
\text { correlation }\end{array}$ & ANOVA & LSD Post Hoc \\
\hline $\mathrm{HO}(\mathrm{IC} / \mathrm{IM}+\mathrm{IP}+\mathrm{ICU}+\mathrm{IF}+\mathrm{BP})$ & $\begin{array}{l}r=0,703 \\
p=0,001\end{array}$ & $p=0,001^{* * *}$ & $\begin{array}{r}p=0,001^{* * *} \\
p=0,009^{* * *} \\
p=0,441\end{array}$ \\
\hline $\begin{array}{c}\mathrm{H} 1 \\
(\mathrm{IC} / \mathrm{IM})\end{array}$ & $\begin{array}{l}r=0,618 \\
p=0,001\end{array}$ & $\mathrm{p}=<0,001^{* * *}$ & $\begin{array}{r}\mathrm{p}=<0,001^{* * *} \\
\mathrm{p}=0,001^{* * *} \\
\mathrm{p}=0,053^{*}\end{array}$ \\
\hline $\begin{array}{c}\mathrm{H} 2 \\
(\mathrm{IC} / \mathrm{ICu})\end{array}$ & $\begin{array}{l}r=-0,031 \\
p=0,425\end{array}$ & $p=0,026^{* *}$ & $\begin{array}{r}p=0,435 \\
p=0,028^{* *} \\
p=0,007^{* * *}\end{array}$ \\
\hline $\begin{array}{c}\mathrm{H3} \\
(\mathrm{IC} / \mathrm{IP})\end{array}$ & $\begin{aligned} r & =0,694 \\
p & =0,001\end{aligned}$ & $p=0,003^{* * *}$ & $\begin{array}{r}P=0,001^{* * *} \\
p=0,042^{* *} \\
p=0,835\end{array}$ \\
\hline $\begin{array}{c}\mathrm{H} 4 \\
\text { (IC/IF) }\end{array}$ & $\begin{array}{l}r=0,393 \\
p=0,006\end{array}$ & $p=0,002^{* * *}$ & $\begin{array}{r}p=0,573 \\
p=0,001^{* * *} \\
p=0,001^{* * *}\end{array}$ \\
\hline $\begin{array}{c}\text { H5 } \\
(\text { IC/BP })\end{array}$ & $\begin{array}{l}r=0,132 \\
p=0,209\end{array}$ & $p=0,005^{* * *}$ & $\begin{array}{r}p=0,115 \\
p=0,024^{* *} \\
p=0,002^{* * *}\end{array}$ \\
\hline
\end{tabular}

Note: ${ }^{* * *}$ statistically significant at $1 \% ;{ }^{* *} 5 \% ;{ }^{*} 10 \%$

Source: Authors' work

Final testing in calculating Pearson's correlation of innovative capacity with innovative appearances and the business performance as 5 phenomena in total established a statistical correlation with the value of $r=0.703$ (Table 2). As the values in the ANOVA test and the LSD post hoc test obtained equally good results, it could be concluded that the main hypothesis (there is a positive correlation between IC and IM, ICU, IP, IF, and BP of SCS organisations) is accepted. Although the two auxiliary hypotheses were not confirmed (regarding the correlation between IC/ICU and IC/BP), it could be determined that the 5 observed phenomena only have the strength together. At the same time, their power is lower, as it happens in life.

\section{Discussion}

The research problems and challenges of interpretation of the obtained results may arise from the assumption that SCS are mainly small organizations, with predominantly manual, still non-automated production, with outdated rather than new technologies, which possibly reduces their innovative capacity and consequently raises the question of their competitiveness. The results of the assessment of $I C$ and its correlation with the IM, ICU, IP, IF, and BP of the SCS organizations, due to the long period of crisis in Croatia (for almost 8 years, from autumn 2008 to 2015/2016), certainly affected the obtained values of responses.

For the first time in Croatia, the research diagnosed the fundamentals of the actual state of the SCS organizations as a special segment of the small shipbuilding production. Part of the research limitation certainly could be attributed to particulars of the SCS, the vessel construction, and production as a specific product. The methodology itself bears certain limitations, such as the selection of the indicators. Since there was no similar research, it was not possible to compare the results. The 
subjectivity is always present in the perception of the questions and the interpretation of the outcomes. The time of recession when the survey was conducted should also be considered as an element of impact.

The recession could have been an incentive for SCS organizations to develop innovative capacities for a successful business, but that was not the case. The entire social, financial, and legislative environment was/is not supportive. While the large shipbuilding organizations were saved, sometimes without common sense, by budget funding, issuing state guarantees, the entire small shipbuilding industry was left to struggle alone. In numerous strategies, partnership agreements, and projects, both in Croatia and the EU, innovations are essential drivers of economic progress. However, there is still a need for boosting the innovation ecosystem in Croatia.

\section{Conclusion}

For the first time in Croatia, this research provided a new methodology for assessing the innovative capacity of SCS organizations and its relationship with innovative management, innovation culture, innovative policy, innovative factors, and business performance of SCS organizations. The IC of organizations undoubtedly influences the creation of new products, services, processes, business and organisational models, marketing, and the use of new technologies, which raise their BP indicators to a higher level. As a result of comprehensive research, the main hypothesis that IC and the total of the 5 observed phenomena are positively correlated has been successfully proven. There is a positive correlation between the IC and IM, The IC and IP, the IC and IF. The increase of IC does not positively correlate with the increase of ICU and the increase of BP of the SCS organisations in Croatia since there are other variables of influence and could be a matter of further investigation. All the obtained results speak of a great need for and importance of innovation management and innovation ecosystem because innovation is an essential driver of economic progress and social wellbeing and a key source of current and longterm competitive advantage.

The limitations of the research and challenges of interpretation of the obtained results may arise from the assumption that SCS are mainly small organizations, with predominantly manual, still non-automated production, with outdated rather than new technologies, which reduces their innovative capacity raises the question of their competitiveness. Part of the research limitation could be attributed to particulars of the SCS, the vessel construction, and production as a specific product. The methodology itself bears certain limitations, such as the selection of the indicators. Since there was no similar research, it was not possible to compare the results. The subjectivity is always present in the perception of the questions and the interpretation of the outcomes.

There is also a need for more research about shipbuilding as a complex, economically significant, and competitive industry. A very demanding production, both large and small shipbuilding, requires a lot of knowledge. Still, at the same time, it is a propulsive industry and development driver of a whole range of human activities and innovation.

\section{References}

1. Bacchiega, E., Lambertini, L., Mantovaini, A. (2011), "Process and product innovation in a vertically differentiated industry", International Game Theory Review, Vol. 13 No. 2, pp. 209-221. 
2. Ganzer, P. P., Chais, C., Pelayo Munhoz Olea, P. M. (2017), "Product, process, marketing and organizational innovation in industries of the flat knitting sector", RAl Revista de Administração e Inovação, Vol. 14 No. 4, pp. 321-332.

3. Gawer, A., Cusumano, M. A. (2013), "Industry Platforms and Ecosystem Innovation", Journal of Product Innovation Management, Vol. 31 No. 3, pp. 417-433.

4. Kiseleva, E. M., Artemova, E. I., Litvinenko, I. L., Kirillova, T. V., Tupchienko, V. A., Bing, W. (2017), "Implementation of Innovative Management in the Actions of the Business Enterprise", International Journal of Applied Business and Economic Research, Vol. 15 No. 13, pp. 231-242.

5. Lee, D. K., Kim, Y., Hwang, I. H., Oh, D. K., Shin, J. G. (2013), "Study on a process-centric modeling methodology for virtual manufacturing of ships and offshore structures in shipyards", The International Journal of Advanced Manufacturing Technology, Vol. 71 No. 1-4, pp. 621-633.

6. Letaifa, S. B., Gratacap, A., Isckia T. (2013). Understanding business ecosystems: how firms succeed in the new world of convergence?, De Boeck, Brussels.

7. OECD (2009), "Fall in shipbuilding set to continue for some time, says OECD Council Working Party on Shipbuilding", available at: https://www.oecd.org/sti/ind/fallinshipbuildingsettocontinueforsometimesaysoecdcou ncilworkingpartyonshipbuilding.htm (30 April 2021)

8. OECD (2018). Oslo manual: Guidelines for Collecting, Reporting and Using Data on Innovation, 4th Edition, OECD Publishing and Eurostat, Paris and Luxembourg.

9. OECD (2021). OECD Science, Technology and Innovation Outlook 2021: Times of Crisis and Opportunity, OECD Publishing, Paris.

10. Rao, J., Weintraub, J. (2013), "How Innovative Is Your Company's Culture?", MIT Sloan Management Review, Vol. 54 No. 3, pp. 29-37.

11. Rubino, F., Nisticò, A., Tucci, F., Carlone, P. (2020), "Marine application of fiber reinforced composites: a review", Journal of Marine Science and Engineering, Vol. 8 No. 1, pp. 1-28.

12. Saverhoff, C. (2013). Competitive Differentiation within the Shipbuilding Industry: The Importance of Competence in the Field of Services, Springer, Gabler.

13. Selyutina, L. G. (2018), "Innovative Approach to Managerial Decision-Making in Construction Business", Materials Science Forum, Vol. 931, pp. 1113-1117.

14. Stawasz, E. (2019), "Factors that Shape the Competitiveness of Small Innovative Companies Operating in International Markets with a Particular Focus on Business Advice", Journal of Entrepreneurship, Management and Innovation, Vol. 15 No. 1, pp 61-82.

15. Tenold, S. (2019). Norwegian Shipping in the 20th Century, Palgrave Macmillan, Cham.

16. Tidd, J., Bessant, J. R. (2020). Managing Innovation: Integrating Technological, Market and Organizational Change, John Wiley \& Sons, Hoboken.

17. Wade, R. H. (2012), "Return of industrial policy?", International Review of Applied Economics, Vol. 26 No. 2, pp. 223-239.

18. Zanze, J. (2021), Assessment of Innovative Capacities of Shipbuilding Organizations in Composition Manufacturing, doctoral dissertation. 


\section{About the authors}

Violeta Šugar is Associate Professor, Head of the Chair of Organisation, Entrepreneurship and Law at the Faculty of Economics and Tourism "Dr. M. Mirković", Juraj Dobrila University of Pula, Croatia, where she teaches International Entrepreneurship, Innovation and Entrepreneurship, Lean Startup, Social Entrepreneurship and Quality Management. She is the author of several scientific papers published and/or presented at international and/or domestic conferences, author and co-author of two books. She is head of the Student Entrepreneurial Incubator of the University of Pula. As a Head of the Quality Board of the Faculty of Economics and Tourism, she managed the Project of the ISO 9001:2015 implementation. Previous work experience in entrepreneurship as a small business owner, media, TV journalist, and banking, as a bank officer, appears to be extremely valuable as a source of case study examples in-class teaching. She has been involved in several international and domestic scientific projects funded by the EU funds and the Croatian Ministry of Science, Education, and Sport. The author can be contacted at vsugar@unipu.hr

Josip Zanze recently retired as a CEO at the Kornati National Park. Most of his active years were dedicated to small shipbuilding, as owner and/or CEO of several SMEs, Drvoplastika, Arausa, Danim, Zanzini, and Vodice Plast. He is a visiting lecturer at the Polytechnic of Šibenik, recently obtained his Ph.D. at the Juraj Dobrila University of Pula, Faculty of Economics and Tourism, "Dr. Mijo Mirković" and published several scientific papers. The author can be contacted at josipzanze@gmail.com 